\title{
Bioanalysis
}

\section{Running ahead of doping: analytical advances and challenges faced by modern laboratories ahead of Rio 2016}

\author{
"...the challenge is constant with new forms of doping being \\ incorporated into the cheaters' arsenals as soon as molecules become \\ available."
}

First draft submitted: 17 May 2016; Accepted for publication: 28 June 2016; Published online: 5 August 2016

Keywords: athlete biological passport (ABP) • chromatography $\bullet$ doping control analysis - external quality assessment scheme (EQAS) • immunoassay $\bullet$ MS $\bullet$ PCR $\bullet$ proteomics

\section{Challenges faced by doping control analysis laboratories}

Doping control is the most demanding field of application for organic molecular analytical chemistry. It unites state-of-the-art technologies focused on complex mixtures present in complex matrices (urine and blood), very low limits of detection, quantitation with low uncertainty and extremely rigorous accreditation (ISO17025 [1] and the World Antidoping Agency [WADA] ISL [2]) with the External Quality Assessment Scheme (EQAS). The External Quality Assessment Scheme comprises not only several sets of blind samples each year but also double-blind samples; this means that any sample received from a client could be an unannounced WADA control.

\section{Source of challenges faced by laboratories}

Boldness on the part of athletes, their entourages and perhaps even their families leads to the abuse of practically anything that might (even through the grapevine) be considered performance enhancing. This is true even if this enhancement comes from a collateral effect, which implies the administration of supratherapeutic doses.

Thus, the challenge is constant with new forms of doping being incorporated into the cheaters' arsenals as soon as molecules become available.

\section{Deterrence innovations in doping control}

Deterrence is now based on being ahead of cheaters by developing methods as soon as molecules appear in the market (even the black market) or have been synthesized and are under evaluation by pharmaceutical companies. Additionally, nontarget-based methods are under continuous scrutiny by WADA-accredited laboratories [3], and intensive intelligence operations back up traditional doping control analysis.

Major breakthroughs in overseeing doping practices include the athlete biological passport in its (thus far) two versions, the hematological and steroidal modules, and the availability of encompassing nontarget techniques such as LC exact mass high-resolution MS, comprehensive GC coupled to MS and multiple target proteomic techniques. In this context, DNA-targeting techniques to overcome gene-doping practices are also a reality [4]. Since 2013, the WADA Prohibited List has included gene-doping strategies using 'therapy-like' gene transfer to enhance sport performance. Detection techniques targeting transgenes such as EPO, IGF1, GHRH, FST and GH1 using PCR-based methods and DNA sequencing rely on direct methods and will certainly expand the analytical window and considerably increase the sensitivity of doping procedure detection. The long-awaited inclusion of molecular biology
Francisco Radler de Aquino Neto

Author for correspondence: Universidade Federal do Rio de Janeiro, Instituto de Quimica LBCD - LADETEC, Av. Horacio Macedo, 1281, Polo de Quimica Bloco C, Ilha do Fundao 21941-598, Rio de Janeiro, RJ Brasil radler@iq.ufrj.br

Vinicius Figueiredo Sarderla Universidade Federal do Rio de Janeiro, Instituto de Quimica LBCD - LADETEC, Av. Horacio Macedo, 1281, Polo de Quimica Bloco C, llha do Fundao 21941-598, Rio de Janeiro, RJ Brasil

\section{Luciana Mirotti}

Universidade Federal do Rio de Janeiro, Instituto de Quimica LBCD - LADETEC, Av. Horacio Macedo, 1281, Polo de Quimica Bloco C, Ilha do Fundao 21941-598, Rio de Janeiro, RJ Brasil

\section{Luciana Pizzatti}

Universidade Federal do Rio de Janeiro, Instituto de Quimica LBCD - LADETEC, Av. Horacio Macedo, 1281, Polo de Quimica Bloco C, Ilha do Fundao 21941-598, Rio de Janeiro, RJ Brasil 
approaches in the doping control field will shed new light on possible gene-transfer doping [4-6].

While these techniques are under intense development, improvements in the sensitivity and selectivity of traditional doping control analysis have also reduced the ability of cheaters to bypass the control system. Of course, this analysis became even more effective due to the now-common practices of unannounced sample collection out of competition, which is supported by an intelligence-gathering system to establish the testing pattern to be enforced.

\section{Analytical technology in doping control: urine analysis}

Hundreds of so-called 'small molecules' from more than 15 pharmacological classes have been identified by GC and LC coupling to MS [7,8]. Several improvements in technology for these standard methods are continuously being undertaken. For example, new triple-quadrupole systems $(\mathrm{QqQ})$ are becoming more sensitive as each new version of the instrument comes into the market. Versions with time-of-flight high-resolution mass spectrometers (ToFMSs) and the recently released high-resolution orbitrap mass analyzer have dramatically enhanced the detection capability. This also allows the detection of 'long-term metabolites' of steroids, which enlarges the detection time frame and will hinder doping practices off-season. A collateral improvement is the selectivity increase, which permits faster analyses and an increase in the number of analytes in the current procedures. Therefore, hundreds of analytes are evaluated with lower cost and fast sample turnover, allowing laboratories to divert resources to new doping control challenges.

\section{"The long-awaited inclusion of molecular biology approaches in the doping control field will shed new light on possible gene-transfer doping."}

The development of a single and rapid analytical method that could accommodate the detection of a huge variety of compounds is a constant demand. For LC, its coupling to QqQ mass spectrometers and orbitrap high-resolution mass analyzers had the same impact as GC coupling. For Rio 2016, a new analytical method for the determination of more than 400 known substances was proposed. It uses a hybrid mass spectrometry system consisting of a quadrupole in line with a trap and a collision cell, followed by an orbitrap mass analyser, that could provide highresolution MS data and structural information (LC-Q-ORBITRAP-MS). This setting allow the application of six different MS experiments, including targeted and nontargeted approaches, within a single 10-min chromatographic run. It also permits direct urine analysis in combination with cleanedup extracts obtained with fast and robust solid-phase extraction, increasing the presence of low-recovery analytes and allowing the detection of conjugated molecules.

Both techniques have evolved to provide reliable, robust and reproducible methods, which permit the improvement of quantitation, even in screening procedures. One of the main goals is that the steroidal module of the athlete biological passport will be automatically filled in with results for all urine samples analyzed. Threshold substances also benefit from a more accurate determination and from obtaining reasonable uncertainty levels for all accredited laboratories. Thus, 'permitted levels' of those substances may be defined with accuracy, reducing the margin for possible controlled misuse by athletes.

GC coupled to a combustion furnace and MS (GC/C/IRMS) for $\delta^{13} \mathrm{C} /{ }^{12} \mathrm{C} \%$ determination, aiming for the discrimination of endogenous and exogenous anabolic steroids, has evolved to produce more sensitive and robust methods and increased instrument reliability. Further developments are envisaged regarding multidimensional heart-cutting sample preparation.

\section{Analytical technology in doping control: blood analysis}

Concerning blood analysis, the hematological passport has proven to be an excellent indirect tool to characterize doping practices, and the hematological parameters will possibly be extended to detect subtler variations in individual profiles.

Enhancement of oxygen transport to the muscles is pursued by dopers from different perspectives, which results in several approaches to detect this malpractice. For homologous blood transfusion performed by flow cytometry, improved target antibodies are being developed to discriminate minor antigens present on red blood cells surface of donor and recipient blood. Additionally, autologous blood transfusion is being targeted and hemoglobin synthetic analogs are easily tracked down by colorimetry and if needed nature gel electrophoresis or LC-MS/MS [9,10].

\section{Analytical technology for peptides \& proteins}

The so-called erythropoietin receptor agonist pharmacological class (e.g., erythropoiesis-stimulating agents and nonerythropoietic receptor agonists), comprising erythropoietin and its biosimilars, ana- 
logs and related substances, have very robust electrophoretic detection methods. They are part of the chemical class of proteins and peptides that have recently become popular among cheaters. This class of substances is also easily detected by immunoassays and proteomic (mass spectrometric) techniques. There are now two different approaches for detection of HGH using immunoassays of the intact protein or its biomarkers (IGF-I and P-III-NP) [11]. The combination of both approaches increases the window and the extent of detection, uncovering the manipulation of the HGH/IGF-I axis independently of the doping substance used. MS is also performed for IGF-I detection, as well as for insulin and its mimetics, proteases, hormone-releasing factors and in the development for the detection of P-III-NP. The number of new peptides and protein drugs has increased over the years in the WADA Prohibited List [12]. During Rio 2016, the doping control laboratory will analyze a great number of samples for the identification and quantification of small peptides and proteins. For this purpose, urine and serum samples will be analyzed using SPE, precipitation and immunoprecipitation techniques, followed by LC-Q-ORBITRAPMS or LC-QqQ together with the standard LC-MS target screening [13]. Proteases may be searched by target analysis or bottom-up proteomics approaches. The use of LC nanoflow systems enhances the detectability of those compounds [14].

\section{Gene doping: the most recent challenge}

Gene doping, despite being a future possibility [15], has been under the scrutiny of WADA-accredited laboratories, and methods for its detection are already operational. Based on real-time PCR and sequencing, the prospective methods seem to be robust and rather simple compared with those applied for proteins and peptides $[4,16,17]$.

\section{References}

1 ISO/IEC 17025:2005. General Requirements for the Competence of Testing and Calibration Laboratories. ISO, Geneva, Switzerland (2005).

2 WADA, International Standard for Laboratories (ISL) (2016).

www.wada-ama.org

3 Thevis M, Kuuranne T, Geyer H, Schänzer W. Annual banned-substance review: analytical approaches in human sports drug testing. Drug Test. Anal. 6(1-2), 164-184 (2014).

4 Baoutina A, Coldham T, Bains GS, Emslie KR. Gene doping detection: evaluation of approach for direct detection of gene transfer using erythropoietin as a model system. Gene Ther. 17(8), 1022-1032 (2010).

\section{Breadth of the fight against doping}

In addition to athlete sample analysis, doping control has evolved to a multitask continuous monitoring program involving several WADA-accredited laboratories around the world that permanently feeds the relevant expert groups with information regarding the possible misuses of substances recently removed from the Prohibited List [3]. WADA is also working with pharmaceutical companies and gathering intelligence worldwide in order to detect doping prospects. This information is used for intelligent target testing and follow-up of procedures and behavior, not only of the athlete's entourage but also of the Internet substances market. Therefore, in addition to the specific detection of dopers, understanding the availability of doping substances and methods is crucial to implementing preventive measures.

\section{Are we truly running ahead of doping?}

One can say that the race is being run at an even quicker pace. Of course, as in any control system, sometimes an action by the controlled party is needed to initiate the action of the controller. However, being so close to the cheaters in terms of worldwide knowledge of the possibilities for cheating allows WADA to quickly halt new doping practices and, in many instances, to be positioned in such a way as to deter athletes from possible wrongdoing.

\section{Financial \& competing interests disclosure}

The authors have no relevant affiliations or financial involvement with any organization or entity with a financial interest in or financial conflict with the subject matter or materials discussed in the manuscript. This includes employment, consultancies, honoraria, stock ownership or options, expert testimony, grants or patents received or pending, or royalties.

No writing assistance was utilized in the production of this manuscript.

5 Baoutina A, Coldham T, Fuller B, Emslie KR. Improved detection of transgene and nonviral vectors in blood. Hum. Gene Ther. Methods 24(6), 345-354 (2013).

6 Baoutina A, Alexander IE, Rasko JE, Emslie KR. Potential use of gene transfer in athletic performance enhancement. Mol. Ther. 15(10), 1751-1766 (2007).

7 Girón AJ, Deventer K, Roels K, Van Eenoo P. Development and validation of an open screening method for diuretics, stimulants and selected compounds in human urine by UHPLC-HRMS for doping control. Anal. Chim. Acta 721, 137-146 (2012).

8 Raro M, Portolés T, Pitarch E et al. Potential of atmospheric pressure chemical ionization source in gas chromatography tandem mass spectrometry for the screening of urinary exogenous androgenic anabolic steroids. Anal. Chim. Acta 906, 128-138 (2016). 
9 Segura J, Lundby C. Blood doping: potential of blood and urine sampling to detect autologous transfusion. J. Sports Med. 48(10), 837-841 (2014).

10 Giraud S. Scientific and forensic standards for homologous blood transfusion anti-doping analyses. Forensic Sci. Int. 179(1), 23-33 (2008).

11 Bosch J, Such-Sanmartín G, Segura J. Tracking growth hormone abuse in sport: performance of marker proteins in a controlled setting. Anal. Chim. Acta 745, 118-123 (2012).

12 WADA Prohibited List (2016). www.wada-ama.org

13 Thomas A, Schänzer W, Delahaut $\mathrm{P}$, Thevis M. Immunoaffinity purification of peptide hormones prior to liquid chromatography-mass spectrometry in doping controls. Methods 56(2), 230-235 (2012).
14 Thomas A, Kohler M, Walpurgis K, Schänzer W, Thevis M. Proteolysis and autolysis of proteases and the detection of degradation products in doping control. Drug Test. Anal. 1(2), 81-86 (2009).

15 WADA. Gene doping. Play True 1, 1-12 (2005).

16 Baoutina A, Alexander IE, Rasko JE, Emslie KR. Developing strategies for detection of gene doping. J. Gene Med. 10 (1), 3-20 (2008).

17 Perez IC, Le Guiner C, Ni W, Lyles J, Moullier P, Snyder RO. PCR-based detection of gene transfer vectors: application to gene doping surveillance. Anal. Bioanal. Chem. 405(30), 9641-9653 (2013). 